\title{
A new combination expands the range of the African araneid spider Singafrotypa (Araneae,Araneidae)
}

\author{
Anna Šestáková1,2, Mikhail M. Omelko ${ }^{3,4}$ \\ I Zoological Museum, University of Turku, FI-20014, Turku, Finland 2 Department of Zoology, Faculty of \\ Natural Sciences, Comenius University, Mlynská dolina, 84215 Bratislava, Slovakia 3 Far Eastern Federal \\ University, Sukhanova, 8, Vladivostok 690950 Russia 4 Gornotaezhnaya Station FEB RAS, Gornotaezhnoe \\ Vil.,Ussuriyski Dist., Primorski Krai 692533 Russia
}

Corresponding author: Anna Šestáková (asestakova@gmail.com)

Academic editor: Yuri Marusik | Received 13 June 2012 | Accepted 4 July 2012 | Published 11 July 2012

Citation: Šestáková A, Omelko MM (2012) A new combination expands the range of the African araneid spider Singafrotypa (Araneae, Araneidae). ZooKeys 207: 79-84. doi: 10.3897/zookeys.207.3522

\begin{abstract}
Study of the syntype of Larinioides subinermis, a species known from Ethiopia only, revealed that it actually belongs to Singafrotypa Benoit, 1962. We redescribe Singafrotypa subinermis (Caporiacco, 1940), comb. n., and provide a key to females of four species belonging to Singafrotypa. A distribution map for all species is provided.
\end{abstract}

\section{Keywords}

Larinioides subinermis, Singafrotypa, redescription, taxonomy, spider, Africa

\section{Introduction}

The small African orb-weaver genus Singafrotypa was found to be restricted to western, southern and central Africa (Fig. 14). It presently contains 3 species: S. acanthopus (Simon, 1907), S. mandela Kuntner \& Hormiga, 2002 and S. okavango Kuntner \& Hormiga, 2002 (Kuntner and Hormiga 2002). Examination of syntypes of Larinioides subinermis revealed its generic affinity to Singafrotypa and therefore expands the known diversity of this genus. Except for the original description based on a female, it was considered in two further taxonomic publications by Grasshoff $(1970,1983)$ who ex- 
amined the types. Grasshoff (1970) indicated that L. subinermis belonged to Cyclosini, although Larinioides is a member of Araneini (Grasshoff 1983) he did not make any formal transfer. When Grasshoff returned the types to MZUF he noted that the species actually belonged to Singafrotypa Benoit, 1962 and considered it as a junior synonym of S. acanthopus (Simon, 1907) (Berdondini and Whitman 2002).

Our study of a syntype of Larinioides subinermis showed that Grasshoff's informal synonymy was not correct. This became evident after studying the recently published revision of Singafrotypa by Kuntner and Hormiga (2002). Although L. subinermis is rather similar to $S$. acanthopus, the type species of the genus, it has clear differences.

In this paper we redescribe Larinioides subinermis and propose a new combination as Singafrotypa subinermis (= Larinioides s.), comb.n.

\section{Material and methods.}

Photographs were made with an Olympus Camedia E-520 camera attached to an Olympus SZX16 stereomicroscope at the Zoological Museum, University of Turku. Digital images were montaged using "CombineZP" image stacking software. Examined material is deposited in Museo Zoologico "La Specola" dell'Universita di Firenze, Florence, Italy (MZUF). The terminology of epigynal morphology follows Kuntner \& Hormiga (2002). All measurements are in millimetres.

Abbreviations: $\mathrm{BL}$ - basal lamella of epigyne; $\mathrm{CO}$ - copulatory openings; EB - epigynal base; LL - lateral lamella of epigyne; MP - median plate of epigyne; $\mathrm{SC}-$ scapus.

\section{Taxonomy}

\section{Singafrotypa Benoit, 1962}

Singafrotypa subinermis (Di Caporiacco, 1940), comb. n. http://species-id.net/wiki/Singafrotypa_subinermis

Figs $1-5,9,13$

Larinioides s. Di Caporiacco 1940: 821, f. 28 (†).

Material. 1 오 Syntype, Coll N72, Mag. №2581, Ethiopia, Lago Regina Margherita on island, 16.1,1938 (L. Di Capporiacco)

Diagnosis. Singafrotypa subinermis can be recognized from other females of Singafrotypa by the relative proportion of the scapus to the epigynal base (ventral view) - tip of the scapus only slightly protruding over the base of the epigyne, and position of copulatory openings on the edge of the epigynal base (Figs 6-9). Unlike S. oka- 

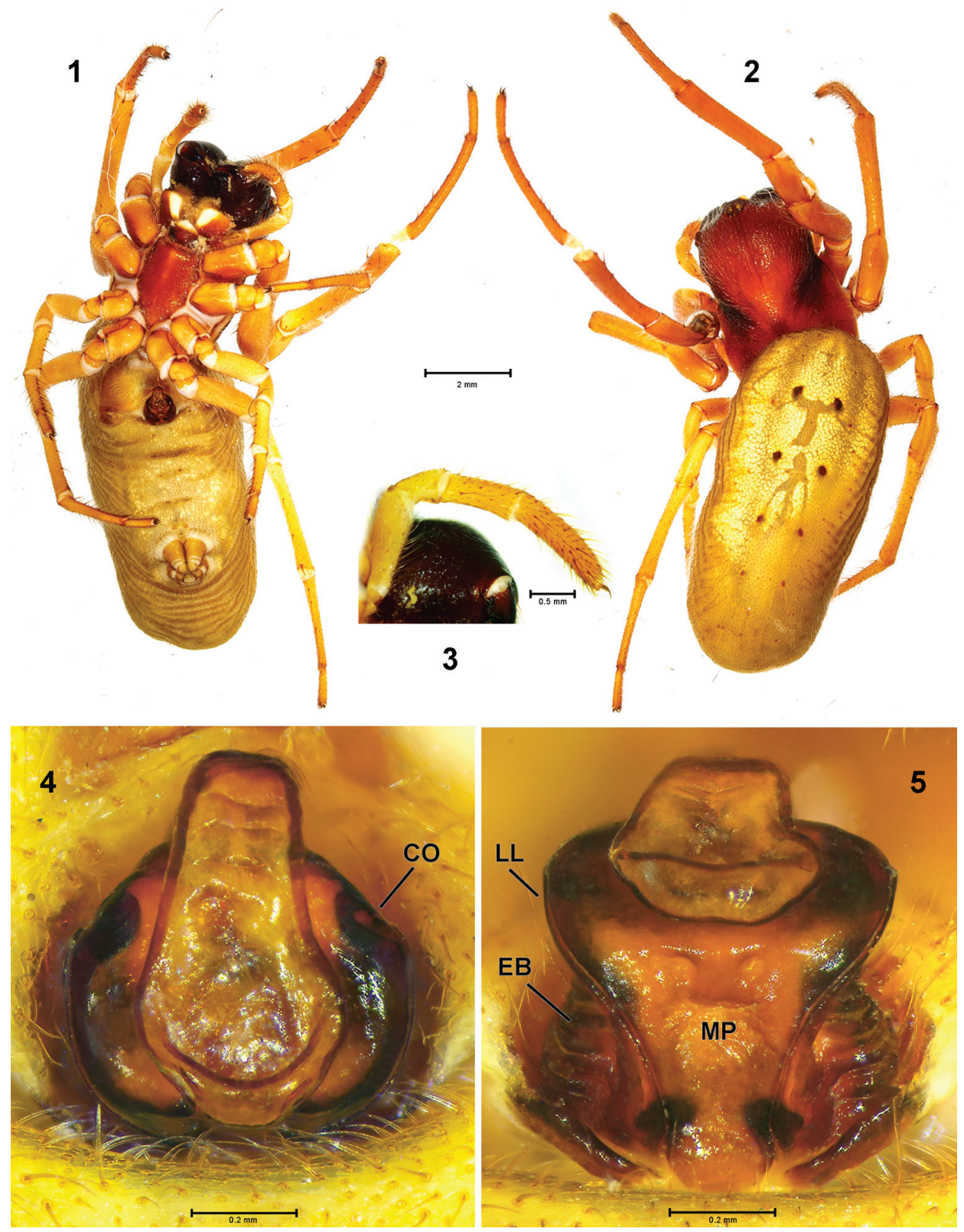

Figures I-5. Female of Singafrotypa subinermis. I ventral $\mathbf{2}$ dorsal $\mathbf{3}$ pedipalp, retrolateral $\mathbf{4}$ epigyne, dorsal 5 ibid., posterior.

vango, it does not have a heart-shaped epigynal base and a long, distinctly wrinkled scapus (Figs 8, 12). It differs from $S$. mandela by the absence of stout macrosetae on the palpal tarsus and paturon, a conical palpal tarsus (Kuntner and Hormiga 2002), 

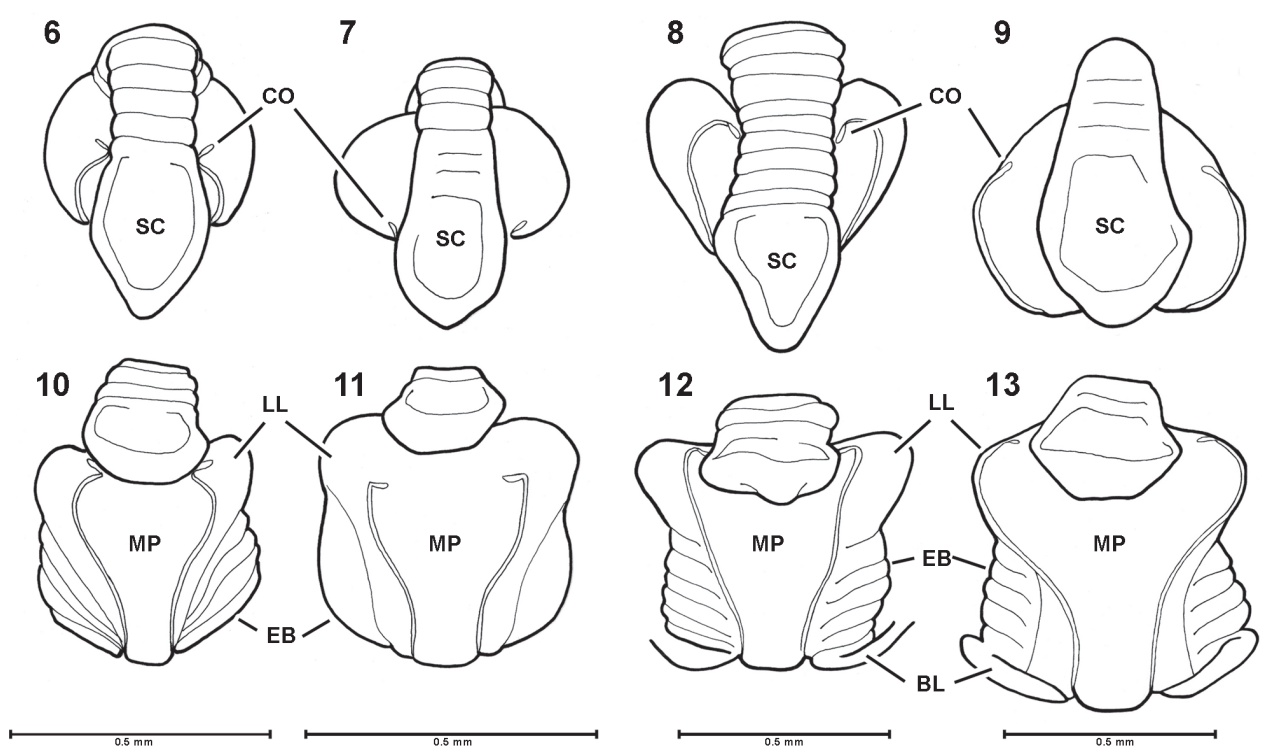

Figures 6-13. Epigynes of Singafrotypa. 6, 10 S. acanthopus 7, I I S. mandela 8, I 2 S. okavango 9, I 3 S. subinermis 6-9 epigyne, dorsal 7-13, ibid., posterior (Figs 6-8, 7-12 redrawn with permission, after Kuntner and Hormiga 2002).

and in the shape of the epigynal base (Figs 7, 11). The epigyne of S. subinermis is the most similar to $S$. acanthopus (Figs 6, 10), but it differs from latter by having fewer wrinkles on the scapus with a round tip (triangular in S. acanthopus), and the shallow depression of the median plate without protruding lateral lamellae (Figs 9, 13).

Description. Female. Total length 11.6. Carapace 4.2 long, 3.2 wide. Length of patella + tibia I 3.8. Carapace uniform red-brown, covered with small white hairs; cephalon protruding. Diameter of AME is 1.3 times larger than PME. Distance between AME 2 times longer than between PME. Chelicerae dark brown; 4 promarginal teeth, 3 retromarginal teeth. Sternum, brown, anteriorly in the middle with short, indistinct pale stripe; longer than wide (Fig. 1). Abdomen elongated, yellowish with two longitudinal brown stripes (Fig. 2), ventrally yellow, paler between epigastric furrow and spinnerets (Fig. 1). Legs yellow. Palp normal, no conical tarsus (Fig. 3). Femur I with 1 prolateral spine; 3 small, dorsal spines; no retrolateral spines.

Epigyne as in Figs 4, 5, 9, 13. Epigyne well sclerotized, protruding, with well developed scapus; epigynal base as wide as long, narrowing anteriorly (dorsal view); basal lamella thin, poorly developed; median plate with shallow depression (under scapus); copulatory openings located anteriorly on the edge of the base; flexible scapus almost as long as epigynal base, indistinctly wrinkled with a round tip (Figs 4, 9).

Distribution. Only known from the type locality, islands of Lake Abaya in Ethiopia (Fig. 14). Singafrotypa subinermis is the easternmost species of the genus. 


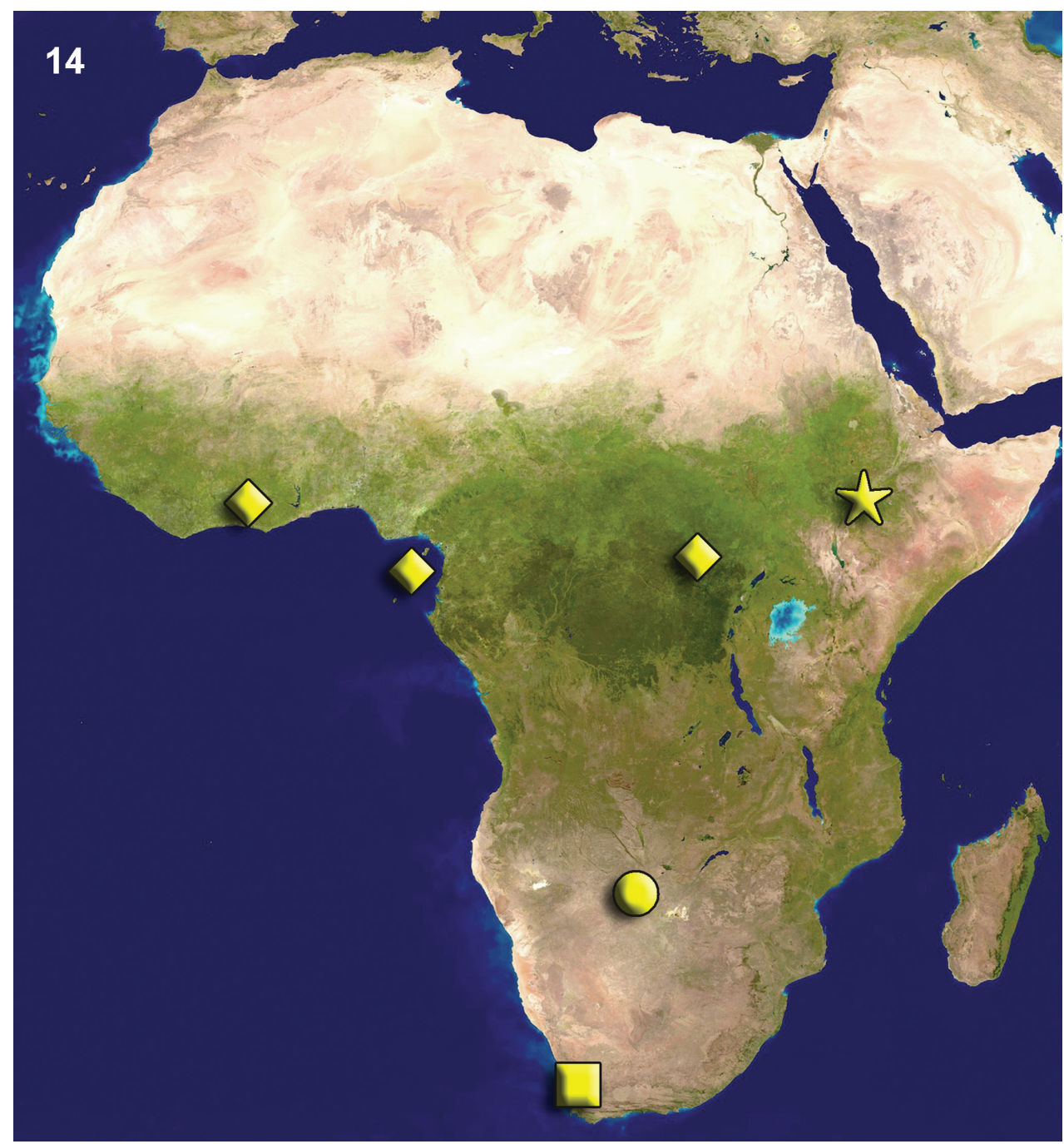

Figure 14. Distribution of the species of Singafrotypa (after Kuntner \& Hormiga 2002 with additional locality of S. subinermis). (http://upload.wikimedia.org/wikipedia/en/2/21/Africa_satellite_orthographic.jpg) -S. acanthopus $\square$. mandela $\bullet$ S. okavango $\star$ S. subinermis.

\section{Key for females of Singafrotypa}

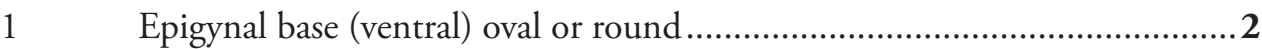

- $\quad$ Epigynal base heart-shaped; long wrinkled scapus (Figs 8, 12).....S. okavango

2 Copulatory openings in the middle or more anteriorly on epigynal base (ventral); epigynal base (ventral) as wide as long; palpal tarsus not conical; chelicerae and palpal tarsus without stout macrosetae. 
- $\quad$ Copulatory openings posteriorly on epigynal base; epigynal base wider than long (Figs 7, 11); stout short macrosetae on palpal tarsus, and laterally on paturon.

S. mandela

3 Scapus with many wrinkles, protrudes over epigynal base (ventral); copulatory openings in the middle of epigynal base (ventral); deep depression of median plate anteriorly with protruding lateral lamellae (posterior) (Figs 6, 10)

S. acanthopus

- $\quad$ Scapus with few wrinkles, does not protrude over epigynal base; copulatory openings anteriorly on epigynal base (ventral); shallow depression of median plate without protruding lateral lamellae (posterior) (Figs 9, 13)

S. subinermis

\section{Acknowledgements}

We thank Sarah Whitman and MZUF for loaning the type material, Matjaž Kuntner for his help in confirming material and permission to redraw figures of epigynes. Special thanks go to Seppo Koponen who allowed us to use equipment in the Zoological Museum of the University of Turku. Last but not least, we thank Yuri M. Marusik who edited the manuscript and supported the visit of Anna Šestáková to Turku, reviewers for their valuable comments, Victor Fet who checked the English of an earlier draft and David Penney for the final correction of this manuscript.

\section{References}

Berdondini I, Whitman S (2002) Cataloghi del Museo di Storia Naturale dell'Università di Firenze - sezione di zoologia "La Specola". XVI. Arachnida, Araneae: Tipi. Atti della Società Toscana di Scienze Naturali. Memorie. Serie B. 109: 119-156.

Grasshoff M (1970) Die Tribus Mangorini. I. Die Gattungen Eustala, Larinia s. str., Larinopa n. gen. (Arachnida: Araneae: Araneidae-Araneinae). Senckenbergiana biologica 51: 209-234.

Grasshoff M (1983) Larinioides Caporiacco 1934, der korrekte Name für die sogenannte Araneus cornutus-Gruppe (Arachnida: Araneidae). Seckenbergiana biologica 64: 225-229.

Kuntner M, Hormiga G (2002) The African spider genus Singafrotypa (Araneae, Araneidae). Journal of Arachnology 30: 129-139. doi: 10.1636/0161-8202(2002)030[0129:TASGS A]2.0.CO;2

Platnick NI (2012) The world spider catalog, Version 12.5. American Museum of Natural History, New York. http://research.amnh.org/iz/spiders/catalog/ [accessed 30 May 2012] 